\title{
USO POPULAR DE MEDICAMENTOS DE ORIGEM VEGETAL EM LACTENTES*
}

\author{
Deborah Forell Bevilácqua*** \\ Edelia del Pilar Neira Huerta*** \\ Lélia Maria Madeira** \\ Maria Tereza Cicero Laganá** \\ Matilde Meire Miranda**
}

BEVILÁCQUA, D. F.; NEIRA HUERTA, E. del P.; MADEIRA, L. M.; LAGANÃ, M. T..

C.; MIRANDA, M. M. Uso popular de medicamentos de origem vegetal em lactentes.

Rev. Esc. Enf. USP, São Paulo, 19(1): 2142, 1985.

As autoras fazem um estudo exploratório num grupo de mães com o propósito de identificar fatos que fundamentem o uso popular de plantas medicinais no cuidado de lactentes. Identificam influências sociais, econômicas e culturais envolvidas e descrevem as implicaçóes para a assistência e o ensino de enfermagem.

\section{INTRODUÇÃO}

O reino vegetal é um verdadeiro tesouro de drogas em potencial, tendo oferecido à humanidade, desde os primeiros tempos, agentes valiosos para curar ou minar seus "incômodos"

O homem sempre experimentou e utilizou substâncias vegetais, minerais e animais para sua alimentação, proteção, vestuário e para combater enfermidades. Com o passar dos tempos, formou-se um corpo de lendas e de conhecimentos populares acerca das virtudes curativas das plantas ${ }^{17}$.

A medicina tradicional - ou indígena ou popular - utiliza a fitoterapia,a, que é a soma de conhecimentos e processos baseados em experiências práticas e observaçðes transmitidas de geração em geração, para curar doentes em diferentes partes do mundo ${ }^{9}$. Segundo NEMEC $^{13}$, dois terços da população dependem, no mundo de hoje, total ou parcialmente, dos métodos de cura usados pelos seus ancestrais.

- Trabalho apresentado à disciplina "Influência dos Fatores Farmacodinâmicos na Assistência de Enfermagem" do curso de Pós-graduação - nível Mestrado da Escola de Enfermagem da USP, 1982.

** Aluna do Curso de Pós-graduação - nível Mestrado da Escola de Enfermagem da USP. 
A fitoterapia no Brasil é, em parte, herança que os índios nos legaram. Deles recebemos a maioria dos nomes das plantas, o conhecimento de sua utilidade e, ainda, seu uso na farmacopéia rústica. Segundo ARAÚJO ${ }^{3}$, é bem provável que o hábito de cultivar ervas medicinais nas hortas das casas tenha provindo dos portugueses, que já utilizavam plantas européias e indianas como "remédios". A cultura negra também contribuiu com "remédios" caseiros que eram usados por curandeiros, parteiras e macumbeiros, principalmente pelo racismo e discriminação sofridos por aquele povo, que geralmente os excluia dó acesso a outros serviços de saúde ${ }^{3}$.

Em artigo publicado na revista ISTO $\mathrm{E}^{15}$ é relatado que a Central de $\mathrm{Me}$ dicamentos (CEME) vem examinando, em seus laboratórios, vinte e uma espécies de plantas medicinais que atendem a inúmeros critérios como o cultivo fácil em todo o país e a tradição de coincidência de uso nas diversas regiões. É relatado também que em nosso país, as plantas medicinais são usadas em larga escala e que pelo menos $50 \%$ dos brasileiros têm o hábito de utilizá-las, sendo conhecidas 300 mil espécies de vegetais, das quais pelo menos 10 mil são usadas com fins medicinais.

$\mathrm{Na}$ Conferência Internacional sobre Cuidados Primários de $\mathrm{Saúde}^{7}$ foi recomendada, aos governos de países subdesenvolvidos e em desenvolvimento, a incorporação dos "remédios" tradicionais de eficiência comprovada, devido a familiaridade dos sistemas médicos populares na comunidade, à eficácia de muitos processos tradicionais de cura; ao fato da medicina tradicional fazer parte da cultura do povo e, finalmente, por ser a medicina popular quase sempre mais barata.

Paralelamente, a Organização Mundial de Saúde (OMS) recomenda, sobre a assistência primária de saúde, que o grupo materno-infantil seja prioritário para receber os cuidados de saúde, por representar a maioria da população nos países em desenvolvimento, e por ser mais vulnerável aos riscos de adoecer e morrer ${ }^{4}$.

$\mathrm{Na}$ nossa experiência como enfermeiras pediátricas sabemos, através das mães, que, ao lado da medicina "moderna" ou alopática, elas têm o hábito de ter em casa, na horta, uns poucos pés de ervas para "remédios de emergência" como o preparo de "chazinhos".

Partindo deste conhecimento e considerando as recomendaçð̃es acima citadas, que se relacionam diretamente com o papel do profissional de saúde junto à população, fizemos um estudo com mães de lactentes $(0-2$ anos) para identificar fatos que fundamentem as implicaçōes do uso popular de medicamentos de origem vegetal na assistência e no ensino de enfermagem.

\section{Objetivos}

- Relacionar as ervas medicinais usadas pelas mães em crianças na faixa etária de 0-2 anos. 
- Relatar a finalidade terapêutica das ervas medicinais relacionadas segundo os usos descritos pelas mães.

- Analisar as implicações do uso de ervas medicinais na assistência e no ensino de enfermagem.

\section{METODOLOGIA}

\section{Local}

O estudo foi realizado no ambulatório de um Hospital Escola de São Paulo e num Centro de Saúde da Secretaria de Estado da Saúde em São Caetano do Sul, devido à facilidade de acesso e à familiaridades das pesquisadoras com as rotinas daqueles serviços, o que facilitou a escolha do local e dos horários mais adequados para a coleta de dados com as mães.

\section{População}

Compôs-se de 72 mães, $51(70,8 \%)$ do ambulatório e $21(29,2 \%)$ do Centro de Saúde, acompanhando crianças entre 0 e 2 anos que compareceram, respectivamente, para consulta médica e atendimento de enfermagem.

\section{Coleta de Dados}

Foi utilizado o formulário em anexo. Através dele verificamos a idade da criança e a procedência da mãe, incluindo na amostra somente aquelas acompanhadas de seus filhos.

Uma vez que a mãe relatasse o uso de ervas medicinais no cuidado do filho relacionamos quais delas pelo seu nome popular bem como para que finalidade ou finalidades, segundo os costumes da mãe.

Pudemos identificar também, através do formulário, o conhecimento das mães acerca do preparo dos chás; da conservação, reconhecimento, obtenção e utilização das plantas, bem como a dose que era dada à criança.

Finalmente, identificamos como a mãe aprendeu a usar o "remédio" e se tinha como hábito a associação de medicamentos alopáticos a plantas medicinais.

\section{RESULTADOS E COMENTÁRIOS}

Das 72 mães entrevistadas, 28 são do Estado de São Paulo e 36, de vários outros Estados do Brasil (Tabela 1). Podemos observar que provavelmente existem hábitos e tradições peculiares às diferentes mães da amostra, pelo fato de serem procedentes de regioes distintas, e que estas diferenças regionais devem influenciar na maneira de como utilizam as plantas, ou seja, como as 
preparam,.que parte da planta utilizam e com que finalidades terapêuticas. Como diz NEMEC ${ }^{13}$ : "Como procedemos depende muito de onde vivemos".

Quanto ao uso das plantas como medicamentos para as crianças, das 72 mães, 64 as utilizam e 8 não o faziam (Tabela 1). Pode-se dizer que, de certa forma, as mães entrevistadas, por estarem presentes nos serviços onde a pesquisa se realizou, têm acesso, pelo menos, a algum tipo de recurso médico; e, mesmo assim, como observamos na Tabela 1, a maioria delas utiliza os "remédios" caseiros para os lactentes. Normalmente, as pessoas que mais fazem uso de remédios caseiros são aquelas que não têm acesso a qualquer tipo de recurso médico ou apresentam fortes razões de ordem econômica ou religiosa para não procurá-los ${ }^{9}$. Por outro lado, aquelas que utilizam remédios caseiros e têm recursos médicos procuram esses serviços porque "medicina moderna tem voz ativa e prestígio", 10 .

Tabela 1 - Procedência das mães que utilizam ou não plantas medicinais,, São Paulo, 1982.

\begin{tabular}{llllc}
\hline \multicolumn{1}{c}{ Procedência } & \multicolumn{2}{c}{ Utilizam } & \multicolumn{2}{c}{ Não Utilizam } \\
& F & $\%$ & F & $\%$ \\
\hline São Paulo (Capital) & 14 & 21,9 & 6 & 75,0 \\
São Paulo (Interior) & 14 & 21,9 & 2 & 25,0 \\
Outros Estados & 36 & 56,2 & - & - \\
\hline \multicolumn{1}{c}{ Total } & 64 & 100,0 & 8 & 100,0 \\
\hline
\end{tabular}

Verificamos, na Tabela 2, que as mães que utilizam as plantas como medicamentos aprenderam o preparo dos chás com pessoas mais velhas da familia, principalmente com sua mãe, sogra ou avós, mostrando-nos a influência dos hábitos culturais das famílias sobre a conduta de seus elementos, pelo menos no que diz respeito aos cuidados com crianças.

As mães acreditam em seus familiares ou mesmo nas "benzedeiras" respeitadas na comunidade porque, geralmente, eles năo se limitam a "prescrever" o chá, mas se interessam pelas pessoas como um todo, fazendo com que as mães dividam suas preocupaçð̄es com eles, acompanhando a evolução do "tratamento" junto com a mãe. Praticam, transferindo-nos para a "medicina moderna", a tão preconizada "medicina integral." 
No dizer de NEMEC"13 "a medicina popular preocupa-se tanto com a mente e a alma do paciente quanto com o corpo, tratando as pessoas no contexto do relacionamento familiar, comunitário e religioso. A medicina moderna, às vezes, trata os pacientes como órgãos isolados e cobertos de pele e as pessoas estão procurando outro tipo de atendimento".

Tabela 2 - Responsáveis pela transmissão da informação sobre o uso de plantas medicinais, São Paulo, 1982.

\begin{tabular}{lrr}
\hline \multicolumn{1}{c}{ Informante } & F & $\%$ \\
\hline Mãe & 44 & 51,8 \\
Sogra & 9 & 10,6 \\
Avó & 8 & 9,4 \\
Pessoa mais velha & 7 & 8,3 \\
Vizinho & 7 & 8,3 \\
Médico & 4 & 4,7 \\
Benzedeira & 2 & 2,3 \\
Tia & 2 & 2,3 \\
Marido & 2 & 2,3 \\
\hline Total & & 100,0 \\
\hline
\end{tabular}

Analisando as Tabelas 1 e 2 conjuntamente, podemos observar que, das mães que utilizam plantas com finalidade ierapêutica, $36(56,2 \%)$ migrantes de outros Estados e $28(43,8 \%)$ migrantes ou oriundas de São Paulo, aprenderam a fazer uso das plantas com a mãe e, em menor grau, com parentes próximos. Podemos inferir que as pessoas tendem a preservar os costumes de suas famílias, aceitando como corretos os hábitos de seus antepassados, inclusive as mães que residem no Estado de São Paulo, onde se encontram os melhores recursos de assistência à saúde.

Através das mães, relacionamos, como mostra a Tabela 3, 31 tipos de plantas utilizadas para os lactentes com finalidade terapêtica. 
Tabela 3 - Plantas medicinais utilizadas por 64 mães, São Paulo, 1982.

\begin{tabular}{|c|c|c|}
\hline Plantas Medicinais & $\mathbf{F}$ & $\%$ \\
\hline Poejo & 41 & 18,2 \\
\hline Hortelã & 40 & 17,7 \\
\hline Erva doce & 38 & 16,9 \\
\hline Camomila & 28 & 12,5 \\
\hline Erva cidreira & 18 & 8,0 \\
\hline Picão & 6 & 2,7 \\
\hline Levante & 6 & 2,7 \\
\hline Agrião & 5 & 2,3 \\
\hline Mentraste & 5 & 2,3 \\
\hline Sabugueiro & 4 & 1,9 \\
\hline Eucalipto & 3 & 1,3 \\
\hline Laranja & 3 & 1,3 \\
\hline Alho & 3 & 1,3 \\
\hline Goiaba & 3 & 1,3 \\
\hline Losna & 3 & 1,3 \\
\hline Limão & 2 & 0,9 \\
\hline Arruda & 2 & 0,9 \\
\hline Santa Maria & 2 & 0,9 \\
\hline Marcela & 1 & 0,4 \\
\hline Pariparoba & 1 & 0,4 \\
\hline Mamona & 1 & 0,4 \\
\hline Hera & 1 & 0,4 \\
\hline Guiné & 1 & 0,4 \\
\hline Manga & 1 & 0,4 \\
\hline Cravo & 1 & 0,4 \\
\hline Canela & 1 & 0,4 \\
\hline Vique & 1 & 0,4 \\
\hline Mate & 1 & 0,4 \\
\hline Pau de rato & 1 & 0,4 \\
\hline Alface & 1 & 0,4 \\
\hline Boldo & 1 & 0,4 \\
\hline Total & 226 & 100,0 \\
\hline
\end{tabular}

A partir dos nomes populares citados pelas mães, identificamos a nomenclatura científica ${ }^{11}$ das plantas utilizadas por elas, no preparo dos chás caseiros. 
Escolhemos os 10 (dez) chás caseiros mais utilizados pelas mães, segundo a freqüência com que foram citados por elas, com a finalidade de conhecer melhor, cientificamente, seus efeitos terapêuticos, e compará-los com o conhecimento popular acerca de seus usos.

\section{DESCRIÇÃO DAS PLANTAS E SUAS PROPRIEDADES}

\section{Poejo}

Nome científico: Mentha pulegium, $L$.

Sinonímia: Erva de São Lourenço, Poejo Real.

As mães utilizam o poejo para: "resfriado" (11), "gripe" (7), "soltar catarro" (7), "tosse" (4), "peito atacado" (1), "bronquite" (1), "canseira" (1), “dor de barriga" (7), "cólica" (2), "diarréia" (1), "vômitos" (1), "vermes" (1), "calmante" (1), "hidratante" (1) e "para dores" (1).

MOREIRA $^{11}$ e MORGAN ${ }^{12}$ referem as seguintes propriedades terapêuticas e usos do poejo:

- é de uso tradicional no tratamento das dores de barriga das crianças recém-nascidas;

- é usado contra tosse e rouquidão;

- é tônico estomacal, aperitivo e carminativo, contra afecções gástricas e gases intestinais.

Comparando-se as propriedades terapêuticas do poejo, descritas na bibliografia citada, e o seu emprego pelas mães, percebemos que as finalidades terapêuticas populares do poejo são coincidentes com seus efeitos científicos no tratamento de afeç̧ões respiratórias e gástricas, exceto pelas suas propriedades antieméticas e vermífugas que não são citadas na bibliografia consultada.

\section{Hortelā}

Nome cientifico: Mentha piperita, $L$.

Sinonímia: Hortelã pimenta, Menta.

As mães utilizam a hortelã nos seguintes casos: "vermes" (2), "resfriado" (3), "gripe" (2), "soltar catarro" (2), "tosse" (2), "dor de barriga" (6), "cólica" (1), "calmante" (6), "hidratante" (3), "diarréia" (1), "vômito" (1) e "soluço" (1).

Propriedades terapêuticas da hortelã referidas por MOREIRA ${ }^{11}$ e MORGAN $^{12}$ :

- é analgésica, acalmando as dores gástricas e intestinais, da mesma forma 
contribuindo para diminuir a exaltação dos reflexos de todo tipo e para acalmar as nevralgias;

- é desinfetante e estimulante da bílis;

- é anti-dispéptica e contra a anorexia e o eretismo nervoso;

- a essência da hortelã produz efeitos cáusticos sobre a pele e as mucosas; quando diluída em água, deixa na boca um frescor agradável;

- em uso externo, a infusão da hortelã, misturada com azeite de oliva, é muito útil nas queimaduras.

A hortelã é bastante usada pelas mães como vermífugo e no tratamento de afeç̧ões respiratórias, embora estas propriedades terapêuticas não sejam citadas na bibliografia consultada.

O uso terapêutico popular e científico da hortelã é coincidente nas afecçбes gastro-intestinais e como "calmante". Outras propriedades científicas da planta, como auxiliar no tratamento de queimaduras, anestésica ou anti-anorética parecem não ser conhecidas pelas mães.

\section{Erva doce}

Nome cientifico: Pimpinella anisium, $L$.

Sinonimia: Anis.

As mães utilizam-na: "nas dores de barriga" (18), "como calmante" (5), "nas cólicas" (4), "prisăo de ventre" (1), "diarréia" (1), "prender intestino" (1), "para boa digestão" (1), "para hidratar" (3), "para febre" (1) e "para soluço" (1).

MOREIRA $^{11}$ e MORGAN ${ }^{12}$ citam as seguintes propriedades terapêuticas e usos da erva doce:

- é um estimulante dos mais úteis, excita suavemente o sistema nervoso e combate a atonia do aparelho digestivo;

- é dotado de propriedades estomáticas, expectorantes, diuréticas e enemagogas bastante pronunciadas;

- é antiespasmódica;

- aumenta a secreção láctea da mulher e regulariza as funçб̃es menstruais;

- o pó das sementes de erva doce misturado, em partes iguais, com o pó de carvão de álamo, choupo ou quina constitui excelente dentifrício, que dá aos dentes perfeita brancura e tonifica as gengivas.

Observamos que: 
- o conhecimento das mães sobre as propriedades da erva-doce como antiespasmódica e como corretora da atonia intestinal corresponde ds descritas na bibliografia citada;

- as propriedades da erva doce como diurético, estimulante e expectorante não foram referidas pelas mães;

Por outro lado:

- a utilização do chá de erva doce como hidratante levanta uma interrogação: - Até onde o seu "efeito diurético bastante pronunciado" permite corrigir ou manter o equilíbrio hídrico da criança?;

- parece-nos que, segundo a bibliografia comentada, não se justifica o emprego da erva doce para "tratar diarréia" e "como calmante" como o fazem as mães, uma vez que ela tem efeito estimulante sobre o sistema nervoso e possui propriedades "enemagogas bastante pronunciadas"11,12.

\section{Camomila}

Nome científico: Matricaria chamomilla, $L$.

Sinonimia: Camomila da alemanha, Marcela, Matricaria.

As mães utilizam-na nas seguintes ocasióes: "dor de barriga" (17), "para hidratar" (5), "como calmante" (3), "para diarréia" (1), "para estômago" (1), "para soluço" (1), "para prender intestino" (1) e "para soltar intestino" (1).

Propriedades e usos terapêuticos da camomila citados por MOREIRA ${ }^{11}$ e MORGAN $^{12}$ :

- o chá de camomila é muito popular é é usado, geralmente, em mamadeiras para crianças de tenra idade, com efeito calmamente e regulador do aparelho digestivo;

- é antiespasmódica, utilizada principalmente nos transtornos nervosos de mulheres e crianças;

- é indicada nas cólicas de estômago, de intestino e de útero (menstruação difícil e dolorosa);

- é utilizada nas enfermidades infecciosas, resfriados, catarros e gripes, devido às suas propriedades sudoriferas;

- é recomendada nas inflamações dos olhos e, finalmente, para combater enxaquecas do tipo nervoso.

Os usos populares da camomila pelas mães são coincidentes com suas propriedades terapêuticas científicas, particularmente nos efeitos reguladores no aparelho digestivo, embora as mães talvez desconheçam as proprieda- 
des sudoríferas do chá de camomila para as afeç̧ões infecciosas.

\section{Erva cidreira}

Nome científico: Melissa officinalis, $L$.

Sinonimia: Melissa verdadeira, Melitéia, Cedrinha, Chá da França.

As mães usam a erva cidreira como: "calmante" (6), "tratamento de cólica intestinal" (5), "febre" (2), "gripe" (1), "disenteria" (1), "soluço" (1), "para falta de apetite" (1) e "para ajudar a arrotar" (1).

MOREIRA $^{11}$ e MORGAN ${ }^{12}$ mencionam os usos e as propriedades terapêticas da erva cidreira:

- é antiespasmódica, sedativa, digestiva, estomática, carminatica e estimulante;

- é indicada contra as digestões difíceis, as cólicas nervosas e as vertigens.

Ao compararmos os fins para os quais as mães administram chá de erva cidreira com as propriedades terapêuticas e usos descritos, podemos observar que existe concordância com vários deles: efeito sedativo, antiespasmódico e carminativo.

No caso de diarréia, seu uso pode ser justificado como hidratante, para repor as perdas líquidas pelas fezes, da mesma forma que na gripe e nos casos de hipertermia.

\section{Picão}

Nome científico: Plambago littoralis

Sinonímia: Carrapicho, Rasteiro e Picão da Praia.

É utilizado pelas mães para: "tratar icterícia" (3), "lesões da pele" (1) e "tratar assadura" (1). $\mathrm{GAN}^{12}$ :

Propriedades terapêuticas do picão descritas por MOREIRA ${ }^{11}$ e MOR-

- é tônico e diurético;

- as folhas em infusão ou cozimento são recomendadas para combater dores reumáticas, doenças das vias respiratórias, febres intermitentes, palpitações e vertigens;

- é antiblenorrágica e antidiarréica, utilizado na diarréia e fệbre palustre e, às vezes, em casos de erisipela.

Os autores se referem a várias espécies desta mesma família de planta. As respostas das mães não nos forneceram subsídios suficientes para determinar 
com exatidão a qual delas fizeram referência. Da mesma forma, a utilização do chá de picão "para uso interno" ou sob forma de decocto "para uso externo", nos banhos ou compressas, não nos ficou claro. Disto resulta a impossibilidade de relacionarmos os usos que as mães fazem desta planta com as propriedades terapêuticas referidas na bibliografia consultada.

\section{Levante}

Nome cientifico: Mentha silvestris

É utilizada pelas mães para: "resfriado" (2), "gripe” (2), “bronquite" (1) e "dor de barriga" (1).

Por pertencer à mesma família do hortelã ${ }^{12}$, supomos que suas propriedades terapêuticas sejam semelhantes. Na bibliografia consultada não encontramos referência sobre o levante, o que nos impossibilita comparar seus efeitos terapêuticos com o seu uso popular.

\section{Agriäo}

Nome cientifico: Nasturtium officinale, $R . B r$.

Sinonímia: Agrião d'água.

O agrião é empregado pelas mães para: "catarro" (2), "tosse" (2) e "pulmão" (1).

MOREIRA $^{11}$ e MORGAN ${ }^{12}$ mencionam as propriedades terapêuticas do agrião:

- contém iodo, cobre, ferro, enxofre, fosfatos e óleos essenciais que o tornam de comprovada utilidade na atonia intestinal, raquitismo, escrufulose, bronquite e toda a sorte de enfermidades catarrais;

- é antiescorbútico por seu importante conteúdo em vitamina C;

- é diurético, vermífugo e combate o reumatismo;

- é desobstruente do fígado;

- em cataplasma é indicado nas feridas da pele;

- por seu valor digestivo e medicinal como salada, impõe-se sobre todas, especialmente para os diabéticos.

Observamos que as mães utilizam o chá de agrião particularmente nas afeç̧ðes catarrais.

Em nossa amostra não encontramos um uso muito difundido do agrião como "remédio" caseiro, apesar de todas as suas importantes propriedades terapêuticas. 


\section{Mentrasto}

Nome científico: Ageratum conyzoides, $L$.

Sinonimia: Mentraste, Mentruz, Manjerona, Catinga de Bode.

É usado pelas mães com os seguintes fins: "doença dos pulmðes" (3), "barriga inchada" (1) e "como alimento" (1).

Propriedades terapêuticas referidas por MOREIRA ${ }^{11}$ e MORGAN ${ }^{12}$ :

- anti-reumática, antidiarréica, febrífuga, carminativa e, tônica;

- útil em resfriados, cólicas flatulentas e uterinas, amenorréia, gonorréia e beri-beri.

Verificamos que, apesar de pouco difundido entre as mães, o mentrasto é utilizado de forma correta por elas, ou seja: como antiflatulento, como tônico e no tratamento de afecções respiratórias.

\section{Sabugueiro}

Nome científico: Sambucus nigra, $L$.

As mães o utilizam no "tratamento da febre" (3) e do "sarampo" (2).

Propriedades terapêuticas e usos do sabugueiro citados por MOREIRA ${ }^{11}$ e MORGAN $^{12}$ :

- tem sido usado no combate ao sarampo e à escarlatina;

- as flores são sudorificas, depurativas e acalmam a tosse;

- as folhas são diuréticas e sua aplicação tópica acalma a dor em pouco tempo;

- a casca é purgante e diurética;

- o fruto é depurativo;

- da semente se extrai um óleo que apresenta numerosas aplicações industriais.

Apesar de todas estas propriedades as mães empregam o sabugueiro sob forma de chá de folhas apenas no combate à febre e ao sarampo.

Constatamos que, conforme a Tabela 4,47 mães $(49,0 \%)$ possuem, em seu próprio quintal, algumas plantas: poejo, hortelã, mentrasto, levante ou sabugueiro.

Quando não existe esta possibilidade, utilizam-se do quintal alheio - 122 mães $(12,5 \%)$ - geralmente do quintal de vizinhas ou amigas, fazendo uso da planta in natura. 
A camomila, erva doce, erva cidreira ou agrião são adquiridos geralmente no comércio - 34 mães $(35,4 \%)$. Outras - $3(3,1 \%)$ - referem que utilizam picão, sabugueiro ou ainda mentrasto através de parentes ou conhecidos que residem no campo.

Tabela 4 - Locais de obtenção das plantas medicinais, São Paulo, 1982.

\begin{tabular}{lrr}
\hline \multicolumn{1}{c}{ Local } & F & $\%$ \\
\hline Quintal próprio & 47 & 49,0 \\
Quintal alheio & 12 & 12,5 \\
Compra & 34 & 35,4 \\
Campo & 3 & 3,1 \\
\hline Total & 96 & 100,0 \\
\hline
\end{tabular}

O fato da maioria destas plantas poder ser cultivadas nos próprios quintais facilita o emprego das mesmas, diminuindo o custo e o tempo gasto para sua aquisição. Quando é necessário comprar, o preço é geralmente inferior ao de medicamentos alopáticos usados para o mesmo fim, reforçando ainda mais a utilizaçđo de plantas medicinais.

Quanto ao reconhecimento das plantas, as mães não mostraram dificuldades. Reconhecem-nas pela forma da planta e da follha e pelo cheiro característico. Nenhuma relatou desconhecer como identificá-las.

Segundo MORGAN ${ }^{12}$ existem aspectos básicos a considerar na utilização de plantas medicinais. É muito importante observar alguns cuidados básicos: seleção, coleta, conservação, dessecação das plantas, as partes das plantas a serem usadas, a maneira de prepará-las, a dosagem e o tempo de cozimento, que variam em cada caso e têm que ser observadas rigorosamente, para que as plantas proporcionem ajuda e alivio. Da mesma forma, cada parte da planta (folhas, flores, frutos, sementes, casca e raizes) deve ser preparada na forma que permita maior extração de seus princípios ativos sob a forma de infusão, decocção ou cozimento, cataplasma, tintura e alcoolaturas, tinturas vinosas ou vinhos medicinais, elixires ou tisanas, de acordo com a finalidade terapêutica exigida em cada caso ${ }^{6,12}$.

Quase a totalidade das mães relatou o uso de plantas sob a forma de chás. Poucas fizeram referência ao uso de "xaropes" que corresponderiam às tin- 
turas. Talvez seja pela facilidade no preparo dos chás e na administração às crianças, ou ainda pela maior facilidade de assimilação do aprendizado de como prepará-los.

Dos chás relacionados pelas mães (Tabela 3), as partes da planta (in natura ou dessecada) mais utilizadas por elas são as folhas. Utilizam-nas sob a forma de decocto. Poucas fazem uso do infuso.

O decocto é fruto da operação de se extrair os princípios ativos de uma substância vegetal, por contato com um líquido em ebulição ${ }^{6}$. $O$ infuso é produto do contato da substância vegetal com água fervendo, em recipiente tampado ${ }^{12}$.

Como, na utilização das folhas, segundo CASTELLANO ${ }^{6}$, a forma indicada para uso é o infuso, verificamos que os chás estão sendo preparados, em sua maioria, de forma incorreta pelas mães, levando provavelmente à modificação ou perda de princípios ativos das folhas por ação do calor. Apesar disto todas as mães confirmaram as propriedades terapêuticas dos chás para as finalidades nas quais elas crêem terem efeito.

Quanto à conservação das plantas medicinais ${ }^{6}$, a maneira de guardá-las, descrita pelas mães, está correta. Quando in natura as folhas são conservadas na geladeira, em vasilhame de vidro ou saco de plástico fechado, sendo desprezadas quando começam a escurecer. As plantas dessecadas, como camomila ou erva doce, que já são adquiridas em embalagens próprias, são conservadas nestas mesmas embalagens ou em vidros fechados, ao abrigo da luz.

Verificamos que não existe um consenso entre as mães quanto à concentração e dose dos chás das plantas relacionadas. Para preparar o chá elas utilizam "um punhado" de folhas ou " 2 ou 3 folhinhas" ou "um tanto da erva". Observamos que algumas delas relacionam o tamanho da folha com a quantidade a ser empregada no preparo. Quando a folha é maior (sabugueiro, agrião) elas utilizam menor quantidade e quando são menores (camomila, erva doce adquiridas no comércio), aumentam a quantidade das folhas para o preparo.

Conforme MORGAN" "é bom lembrar que a planta fresca é, em termos gerais, superior à dessecada. Com relação aos efeitos das doses a serem empregadas, toda planta dessecada sofre uma perda natural, que necessariamente eleva seu poder medicamentoso. Esta perda natural faz com que entre uma substância fresca e a mesma dessecada, haja uma diferença que pode fixar-se, em termos médios, em uma relação de $2: 7$, ou seja, se da planta fresca empregamos 7 partes, da dessecada devemos empregar 2 partes".

Com relação à dose administrada à criança, a maioria das mães oferece o "chazinho" conforme a aceitação da criança. Dizem ser necessário que o chá seja "fresquinho", mas "a quantidade nâo tem importância", podendo 
ser dado "à vontade", até mesmo "quando faz muito calor", "sem a criança ter nada", ou seja, para hidratar.

Um número menor de mães está preocupado com a posologia e acham que, para a criança, não pode ser dada quantidade "muito grande nem muitas vezes ao dia". Administram, por exemplo, uma colher de chá 2 (duas) vezes ao dia.

MORGAN"12 refere, ainda, "que é necessário muito cuidado na dosagem: sempre respeitar a dose indicada pelo médico ou especialista. É preciso pesar a droga numa balança que pese com precisão até a casa das gramas. Caso não haja balança, existe uma lista das principais equivalências como colherinha de café; colher de sopa; punhado (folhas ou sementes); pitada; xícara ou gota, de azeite de oliva ou de tintura".

CASTELLANO" acrescenta: "É importante lembrar que as preparações fitoterápicas produzem efeito se ingeridas com regularidade, na medida e na hora certa", citando por exemplo, que vermifugos, diuréticos e depurativos devem ser tomados no desjejum ou que sedativos e laxativos devem ser tomados antes de deitar.

Quanto à utilização dos chás juntamente com medicações alopáticas, constatamos que, das 64 mães que fazem uso dos chás com finalidades terapêuticas (Tabela 1), 35 delas $(54,9 \%)$ administram predominantemente antitérmicos e analgésicos com os mais variados chás; erva doce, camomila, poejo, hortelã, laranja, limão, goiaba e erva cidreira. Relatam, em menor grau, a administração, juntamente com os chás caseiros, de antibióticos, complexos vitaminicos, antiespasmódicos, antieméticos e broncodilatadores. Relatam que os medicamentos alopáticos são dados com os chás e, às vezes, até dissolvidos nele e que o chá "pode ser dado com qualquer coisa", "nunca faz mal".

Por outro lado, encontramos 29 mães $(45,1 \%)$ que não associam chás caseiros com medicações alopáticas. Administram os chás ou administram os medicamentos (Tabela 5).

$\mathrm{O}$ fato de muitas mães, como mostra a Tabela 5, associarem medicamentos alopáticos com diversos chás, nos faz questionar:

- O que se sabe sobre esta "interação medicamentosa"?

- Ao se prescrever e/ou orientar as mães quanto à administração de um medicamento alopático, é indagado se elas costumam utilizar plantas medicinais?

Para NEMEC 13 "as desvantagens da medicina tradicional, muitas vezes são fáceis de constatar: instrumentos e substâncias usadas não são padronizadas de acordo com critérios higiênicos e científicos. As mãos nem sempre são lavadas com freqüência. As plantas têm nomes diferentes nos diversos 
Tabela 5 - Administração de medicamentos álopáticos associados a chás caseiros pelas mães, São Paulo, 1982.

$\begin{array}{llll}\text { Mães } & \text { F } & \% & \text { Medicamentos }\end{array}$

Administram

35

antitérmicos, analgésicos, antieméticos, Administram

34,9
tibióticos, complexos vitamínicos.

Não administram $29 \quad 45,1$

Total

$64 \quad 100,0$

países (e nas diversas regiōes). Falta precisão e padronização na dosagem e no preparo e, quando "remédios caseiros" são combinados com medicamentos "modernos", o resultado pode ser prejudicial.

Ao nosso ver esses aspectos devem ser considerados e analisados dentro da estrutura sócio-econômica-religiosa de cada população, pois, segundo a mesma autora ${ }^{13}$, "a medicina tradicional pode ter efeito espetacular curando as pessoas em sua própria cultura, de acordo com o seu conceito das causas da doença".

\section{IMPLICAÇÕES PARA A ASSISTÊNCIA E PARA O ENSINO DE ENFERMAGEM}

As práticas da medicina popular necessitam melhores observaçðes e não podemos descartá-las, simplesmente, sem estudar seu contexto, sem participar da vida dos que vivem estas experiências. De fato, não podemos omitir que a formação profissional da enfermeira, às vezes, dificulta encarar a saúde como o leigo comumente a percebe. Por isso, muitas vezes, os leigos não se sentem à vontade com os profissionais de saúde e procuram apoio nas práticas da medicina tradicional porque "damos explicações diferentes para a doença e usamos um enfoque diferente para a cura, do que estão acostumados" 10 .

A cultura sanitária da comunidade, incluindo curiosas, benzedeiras, líderes comunitários, bem como a família do cliente, como um todo, deve ser respeitada, pois tem influência nas práticas de saúde que o leigo adota. Conforme CANDEIAS \& MARCONDES ${ }^{5}$, as práticas de saúde dos indivíduos prendem-se também às circunstâncias que os envolvem. Estas circunstâncias podem prender-se a normas sociais, valores culturais, papéis desempenhados e coerção social, entre outros fatores. 
Neste sentido os serviços de saúde têm tido pouco a ver com a saúde do povo e não têm conseguido proporcionar saúde, porque desprezam o papel desempenhado por valores culturais, normas e comportamentos sociais da comunidade e mesmo os padróes de saúde e doença próprios de cada grupo social (desde famílias até comunidades inteiras). Esquecemos que "as pessoas da comunidade, são um grande potencial de recursos não explorados"

Por outro lado, devido ao fato da transmissão de conhecimento sobre a utilização de plantas medicinais ser feita predominantemente, de geração em geração por leigos das comunidades, algumas indicaçðes do seu uso podem ser fruto apenas de crenças e superstiçōes, sem fundamentação científica. Por isso a enfermagem não pode aceitar ou prestigiar todos os recursos tradicionais que as comunidades valorizam, sem antes questionar sua validade. Algumas práticas populares são realmente prejudiciais, como colocar estrume de vaca no cordão umbilical de um recém-nascido ou aplicar emplastos de certas ervas "mastigadas" sobre ferimentos por queimadura. "Atribuir um aspecto romântico às práticas prejudiciais não é nenhum favor para o povo. Sem os controles exercidos por uma comunidade tradicional, os curandeiros (ou benzedeiras) podem aproveitar-se do despreparo de doentes e familiares, principalmente quando são pobres e ignorantes. Pode ser um paraíso para charlatōes"'.

A população urbana é envolvida pela variedade de recursos médicos altamente sofisticados, condicionado-a a consumir tudo que lhe é oferecido, inclusive o atual modismo do uso de ervas naturais. Na Europa e Estados Unidos, medicamentos "naturais" assim como alimentos "naturais" tornaram-se moda dispendiosa e manuais sobre ervas estão nas listas dos livros mais vendidos $^{9}$.

NEMEC ${ }^{13}$ questiona: "A medicina tradicional pode sobreviver num país industrializado, onde os valores da comunidade estão passando para uma mentalidade própria ao consumismo?"

As populações mais afastadas dos grandes centros urbanos, que recebem pouca ou nenhuma influência dos efeitos modernos da propaganda e consumismo atuais, preservam os hábitos das tradições locais. Quando migram, por escolha ou necessidade, para outra cultura, que adaptação às regras, crenças e valores desta cultura podemos esperar?

Devido a estas contradiçð̃es e à miscelânea de populações com valores culturais regionais diferentes que habitam os principais centros urbanos, devido também às migraçð̃es, estabelece-se uma variedade de crenças e tabús que freqüentemente são controversos, aceitos por uns e por outros negados ou negligenciados.

Diante deste quadro é preciso que a enfermagem tenha conhecimento das propriedades terapêuticas das plantas, para reconhecer suas indicaçð̃es eficazes e descartar as práticas nocivas, à luz da ciência moderna, procuran- 
do, inclusive, integrar o conhecimento tradicional ao conhecimento moderno, contribuindo para os cuidados de saúde na população. Cabe ressaltar o fenômeno do efeito placebo. Saberemos detectar quando o "chá" poderá ser administrado como efeito sócio-psicológico, necessitando, porém de outros recursos médicos? Segundo colocação de ARAÚJO "o chá é água fervida, livre de micróbios e, ingerí-lo, mal não fará!".

Atualmente, com as novas estratégias adotadas pelos sistemas de saúde visando a "saúde para todos no ano 2000", através dos cuidados primários de saúde, a enfermagem assume novo papel, inclusive na formação do pessoal auxiliar de enfermagem. Entre as estratégias, relaciona-se a utilização dos recursos da comunidade, incluindo o conhecimento das plantas medicinais "que são recursos eminentemente populares"?

Outro fato é a tendência observada nos serviços de saúde, de se delegar ao pessoal auxiliar a identificação de determinadas patologias com permissão para a indicação de tratamentos padronizados ${ }^{16}$.

$\mathrm{Na}$ legislação atual da enfermagem, à enfermeira é proibida a prescrição de medicamentos. As plantas, no entanto, possuem princípios ativos que sugeririam uma "prescrição medicamentosa".

O Código de Deontologia de Enfermagem, ao estabelecer, no artigo 9?, as proibiçб̄es ao enfermeiro cita a prescrição de medicamentos como uma delas e determina, como ressalva, as ocasiōes previstas na legislação vigente e os casos de extrema urgência. A penalidade prevista para esta proibição varia de advertência verbal a suspensão do exercicio profissional ${ }^{8}$.

Outros pontos a considerar para a enfermeira poder assumir o seu novo papel requerido nas tendências atuais ${ }^{1,2}$, são os seguintes:

- o mundo moderno ainda não sabe analisar uma planta a fundo. Existem certas enzimas que não sabemos isolar, mas sabemos que são muito eficazes $^{9}$;

- centros de pesquisa como os do México e Zaire, ainda procuram descobrir o valor terapêutico dos remédios caseiros sobre efeitos colaterais prejudiciais ${ }^{9}$;

- remédios caseiros administrados com medicamentos modernos podem ter efeito prejudicial $^{13}$;

- falta ainda uma nomenclatura padronizada para os remédios de ervas e a qualidade da matéria-prima varia muito e depende do tempo, do lugar, seleção e condições de estocagem ${ }^{9}$;

- como nem todas as propriedades, mesmo as dos remédios de maior eficácia, são bem compreendidas, é preciso haver cuidado no uso de plantas em escala maior ${ }^{9} ; \mathbf{e}$, 
- um dos cuidados gerais a serem tomados para evitar intoxicação acidental por plantas é "não tomar chás medicinais preparados com plantas de procedência duvidosa ou indicadas por pessoas leigas no assunto"14.

A enfermeira precisa, portanto, rever sua legislação profissional e, principalmente, acrescentar este novo conhecimento sobre a medicina tradicional na sua formação profissional, para estar apta a exercer suas novas funçб̃es $^{1,2,10}$ exigidas no contexto de saúde que ora vivemos.

Cabe ressaltar que, mesmo nas regiōes onde o uso de ervas medicinais é tradicionalmente aceito nas comunidades, como África, Ásia, ou mesmo nas Américas, estão sendo feitos estudos ou modificaçðes quanto à legislação específica para o uso das plantas no meio médico, incluindo as curandeiras tradicionais, e também para proteger as ervas do risco da extinção de algumas espécies ${ }^{9}$.

\section{CONCLUSÕES}

A utilização de plantas com fins medicinais vem constituindo um vasto campo de pesquisas que fornecerão importantes subsídios geradores de mudanças na sistematização da assistência de enfermagem e que refletirão na identificação e preparo das plantas medicinais e no uso adequado quanto à dosagem, indicações específicas, limitaçð̄es e riscos de utilização das mesmas.

É necessário rever a legislação de enfermagem e considerar a relação inter-profissional da enfermeira para delimitar as atribuições próprias do médico e da enfermeira, possibilitando sua proteção legal, principalmente em regiōes carentes de médico. Para tanto é preciso uma definição conjunta entre as associaçбes médicas e de enfermagem.

BEVILẢCQUA, D. F.; NEIRA HUERTA, E. del P.; MADEIRA, L. M.; LAGANÁ, M. T. C.; MIRANDA, M. M. Popular use of medicinal plants in infancy: implications for nursing. Rev. Esc. Enf. USP., São Paulo, 19(1): 2142, 1985.

An exploratory study is made by nurses with a group of mothers with the purpose $e$ of identifying reasons for the popular use of medicinal plants by mothers caring for their $r$ children within the 0-2 years age range. Influence of the social, economical and cultural $t$ factores involved are considered. The implications of this data for nursing care and for ${ }^{-}$ teaching it are described. 


\section{REFERENNCIAS BIBLIOGRÁFICAS}

1. ADAMI, N. P. Experiências sobre a atuação da enfermagem na atenção primária de saúde. Enf. Novas Dimens, Sáo Paulo, 4(4): 212-21, 1978.

2. ADAMI, N. P. Novas tendências da enfermagem de saúde pública. Rev. Gaúcha Enf., Porto Alegre, 2(2,3,4): 73-82, 1980.

3. ARAOUJO, A. M. Medicina rústica. 2. ed. Sáo Paulo, Nacional, 1977.

4. BRASIL, Ministério da Saúde. Conferência Nacional de Saúde, sạ. Programa Materno-infantil. Brasilia, 1975.v. 2.

5. CANDEIAS, N. M. F. \& MARCONDES, R. S. Diagnóstico em educação em saúde: um modelo para analisar as relaçóes entre atitudes e práticas na área da saúde pública. Rev. Saúde públ., São Paulo, 13: 63-8, 1979.

6. CASTELLANO, O. Introduçio à fitoterapia São Paulo, EPUSP, 1981.

7. CONFERENCIA INTERNACIONAL SOBRE ATENCION PRIMARIA DE SALUD, 19, AIma Ata (URSS). Atención primaria de salud: informe conjunto. Genebra, Organización Mundial de la Salud, 6-12, 1978.

8. CONSELHO FEDERAL DE ENFERMAGĖM. Código de Deontologia de Enfermagem - Código de Infraçóes e Penalidades. Brastlia, 1979.

9. CONTACT. Redescoberta de um recurso antigo... Nova visto da medicina tradicional. Sáo Paulo, 16: 2-24, 1981. (Coletânea de artigos fornecidos pela Organizaçăo Mundial de Saúde)

10. CONTACT. Atençto Primária no Brasil : experiências. Sáo Paulo, 34: 3-16, 1984. (Coletânea de artigos.)

11. MOREIRA, F. As plantas que curam. Sáo Paulo, Hemus, 1978.

12. MORGAN, R. Enciclopédia das ervas e plantas medicinais. São Paulo, Hemus, 1979.

13. NEMEC, J. Nova visáo da medicina tradicional. Contact, Sáo Paulo, 16: 2-17, 1981.

14. PANIZZA, S. \& SCAVONE, O. Plantas tóxicas, 2. ed. Sáo Paulo, EDUSP, 1981.

15. PLANTAS NO TUBO de ENSAIO. Isto é, Sáo Paulo, 332: 38, 4 maio, 1983.

16. WERNER, D. Onde ñ̃o há médico. Sáo Paulo, Ediçőes Paulinas, 1979.

17. WRIGHT, H. N. \& MONTAG, M. Tratato de farmacológia y terapeutica. 7. ed. Madrid, Interamericana, 1966. 


\section{ANEXO \\ QUESTIONÁRIO No}

1. Entrevistado (mãe)

2. Idade da criança

3. Procedência da mãe

Cidade

Estado

4. Usa ou já usou alguma planta como remédio para a criança?

SIM

NAO

5. Qual(is) é utilizada? Nome.

6. Para que fim(s)? Sinais e sintomas.

7. De que maneira utiliza?

7.1. Que parte da planta?

7.2. De onde obtém?

7.3. Como reconhece a planta?

7.4. Como prepara?

7.5. Conservação.

7.6. Dose que é dada à criança.

8. Como aprendeu a usar o remédio? 
9. Costuma usar remédio caseiro junto a outras prescritas pelo médico? SIM

9.1. Quais?

NAOO

政 